Cheong, C., Coldwell-Nielson, J., MacCallum, K., Luo, T., \& Scime, A. (Eds.). (2021). COVID-19 and Education: Learning and Teaching in a Pan-

Santa Rosa, California: Informing Science Press. (pp. xx-xx).

\title{
Student Academic Integrity in Online learning in higher education in the era of COVID-19
}

\author{
Carolyn Augusta and Robert D. E. Henderson \\ LINK TO PUBLISHED VERSION
}

\section{Abstract}

We examine strategies for reducing academic misconduct in online courses both when the instructor must move a course from in-person to online, and when an online course is developed intentionally. In the winter of 2020, courses that would not traditionally have been developed for web-based learning were retrofitted mid-term to accommodate restrictions introduced by the COVID-19 pandemic, which may have introduced additional challenges regarding assurance of academic integrity. Beyond discussing plagiarism, which is thought of as one of the most common types of academic dishonesty (Marques et al., 2019), we consider subscription-based digital resources which may enable cheating on a broader scale. We review the motivation behind many instances of academic dishonesty and suggest methods for mitigation. We emphasize the need for promoting honesty, not just preventing dishonesty. Although we focus our examples on large introductory-level quantitative courses, our strategies may be applied more broadly. In particular, we address the question: as an instructor, how can I prevent academic misconduct to the best of my ability in an online environment during a global pandemic?

\section{Introduction}

Before the time of COVID-19, academic dishonesty was studied from both an in-person and online learning perspective (Baron \& Crooks, 2005; Greaser et al., 2008; Marques et al., 2019; McCabe et al., 1999; Peterson, 2019). McCabe et al., 1999 examined the reasons behind cheating and made suggestions regarding instructor interventions; however, at the time of publication, web-based courses were still in their 
infancy. It has been suggested that student perceptions of cheating differ between in-person and online components (Kocdar et al., 2018). Indeed, in the same work, a survey of students included a question aimed at capturing concern regarding a switch from face-to-face to online assessment. The authors found that the number of students who anticipated an increase in cheating was greater than the number of students who did not, foreshadowing the concerns regarding student trust of online assessments during the pandemic.

It has also been documented that the use of technology has changed students' perception of ethics over time (Lau et al., 2012), and many previous works examining dishonest behaviour have focused on inperson classes (Marques et al., 2019). One study found that academic misconduct is more prevalent in traditional classroom settings than in a distance-based format (Stuber-McEwen et al., 2009), contradicting a previous hypothesis put forth by George and Carlson (1999) that distance-based students would cheat more often than their in-person counterparts. Combined with the conclusions of Kochdar et al., 2018, we can surmise that although students may feel there is a higher likelihood of cheating in an online environment, this lack of trust in online assessments does not always lead to an increase in dishonest behaviour. It is also possible that that there is an increase in academic dishonesty in an online setting that has previously gone undetected. A number of factors may be at play, including a possible reduction in the quality of student-student interaction in online environments versus on campus, leading to more stilted information flow instead of a free exchange of ideas. For example, the presentation of the self changes in online and in-person environments, which may impact the quality of communication (Bullingham \& Vasconcelos, 2013). There may also be an altered sense of accountability in digital submissions.

Related to the issue of student trust in online assessment methods is the perception of educational quality in an online environment. If students believe the quality of education they are receiving is low, they may be less likely to invest in the learning outcomes and hence more likely to participate in dishonest behavior. Quantitative courses are often considered difficult by students (Hallett, 2000), and it has been reported that students might prefer to learn difficult concepts in person (Jaggars, 2013). Another study found that students believe an online learning environment does not promote a deep critical understanding of course content (Holzweiss et al., 2014). These factors may interact to form a 
perfect storm that increases the likelihood of academic misconduct when students are required to move to an online setting.

The rapid switch to online learning in the winter of 2020 resulted in a unique confluence of web-based and face-to-face course environments. While this issue has been explored on a more gradual timescale (Beckman et al., 2016; Keramidas et al., 2007), the rapid onset of forced remote learning has sparked a few reports already on instructor and student experiences in this arena. A study published after the winter 2020 term indicated that $93 \%$ of instructors surveyed believed students were more likely to cheat in an online environment than an inperson environment (Wiley, 2020), agreeing with the previouslydiscussed student perceptions uncovered by Kochdar et al., 2018.

Avoiding academic misconduct is of particular concern in the development of online assessments in quantitative courses. One group has published survey results on a course experience after the arrival of COVID-19 for both students and faculty to this effect (Asgari et al., 2020). Another recent study reporting experience from this same term has discussed that revamping an exam from an in-person to an online format may be accomplished through the use of a test bank, reducing instances of cheating (Clark et al., 2020). Although this is one possible avenue to pursue, we explore additional options. The online course environment has changed dramatically, and different strategies are now necessary to promote honest behaviour and discourage cheating.

This chapter is organized as follows. In the next section, we discuss some of the broader issues pertaining to academic integrity in online courses. We present data from a large Canadian university on recent trends in student academic misconduct and highlight a spike in cases generated directly from online subscription-based tutoring services used during final exams. The particular issue of maintaining engagement with the students on moving to remote delivery from a course that is typically taught in-person is then addressed in the context of enhancing academic integrity. Next, we dive into a discussion of specific course components and their possible vulnerabilities to violations of academic integrity and present options which might both benefit honest scholarship and hinder dishonest conduct. Finally, we offer general concluding remarks and a condensed list of our recommended strategies for enhancing academic integrity when moving courses online, either on short notice or by initial design, in the context of the current pandemic. 


\section{Issues and Strategies for Academic Integrity}

The shift to remote learning in the winter of 2020 created a unique type of blended course - a course in which learning is partly online and partly in-person (Kocdar et al., 2018). As a result, students and instructors had already developed teaching and learning tools and strategies based on a fully in-person format, and many struggled to adapt to the new format. For example, students who relied on the structure of lectures to guide their time management may have had little guidance on how much time to spend on an online course per week (Reynders \& Ruder, 2020). Additionally, when it comes to testing, students who excel at a more traditional format - in which they can flip from page to page and tackle the easy questions first - may have been pigeonholed into completing one question at a time as it appeared on a computer screen if online assessments were converted into such a format as a means to discourage possible cheating.

Instructors have had limited time to adapt their course material during the present pandemic, and limited options: they could record complete lectures and post them on a course website, but that would mean students would have to download each video. Those with poor internet connections may not be able to access that content. Instructors could instead provide readings from the textbook, but this strategy may reduce engagement. Some instructors might opt to cease the course entirely and give students the grade they had at that time in the course, which is likely an unpopular strategy. We refer the reader elsewhere in this book for further discussion of transition options; the salient point with respect to academic integrity is that the myriad available options have varying degrees of impact on the potential for academic misconduct. Indeed, academic integrity in online courses has been the topic of several studies (e.g., Lee-Post \& Hapke, 2017; Mastin et al., 2009; Patnaude, 2008; Peterson, 2019), though the COVID-19 pandemic presents unique challenges with both mid-term switching of the delivery mode, and likely several terms of remote delivery before moving to an on-campus format.

\section{Recent Instances of Online Academic Misconduct}

This struggle on both sides, combined with the stress of the pandemic, may have resulted in an increased number of instances of academic misconduct. For example, in two large quantitative courses at a univer- 
sity in western Canada, there were over 20 formal cases of academic misconduct heard, when in previous terms there had been none. At that same university, the number of formal academic misconduct cases heard in 2020 nearly doubled from the previous year, and was the largest recorded number in the last decade (see Figure 1). In the large quantitative courses, all of the misconduct cases involved use of a subscription based digital resource that charged students a monthly fee in exchange for tutor-provided answers to posted questions. The questions, posted by the students, were available through a search engine; the answers were protected by a paywall. Anecdotally, it has been found by the authors that many instructors across Canada have had similar experiences which some consider to be theft of intellectual content.

\section{The Case of Online Subscription-based Tutoring Services}

Some websites that offer services described above also offer legitimate web-based tutoring. Many of these sites are promoted on social media by other students, increasing the appeal to students who are struggling. These sites have been described as problematic (Streseman \& Millican, 2020), as students may be unable to differentiate between true tutoring and the provision of answers for a fee. There are many such sites, with more created frequently, and thus blocking these sites or taking legal action against them is likely infeasible. Instead, a more indirect approach becomes necessary. Instead of searching for these websites and demanding removal of content (which may be possible according to the site's policies), it would be more efficient to disincentivize students from posting in the first place.

One possible avenue to pursue would be the discussion of these sites at the beginning of term, explaining the potentially problematic nature of these sites and risks, including mentioning that the students are the only ones who face repercussions if they are caught committing academic misconduct in this manner - the websites face no consequences. This strategy has yet to be studied formally in the current pandemic setting. It is anticipated that when the instructor exposes the darker side of these websites, students who have heard of them already will be more likely to avoid them, and students who have not heard of them will not be more likely to use them. Some instructors have expressed apprehension regarding this course of action, as it may amount to inadvertent advertising of these websites. We believe if individual website names are not mentioned, such concerns may be abated. 


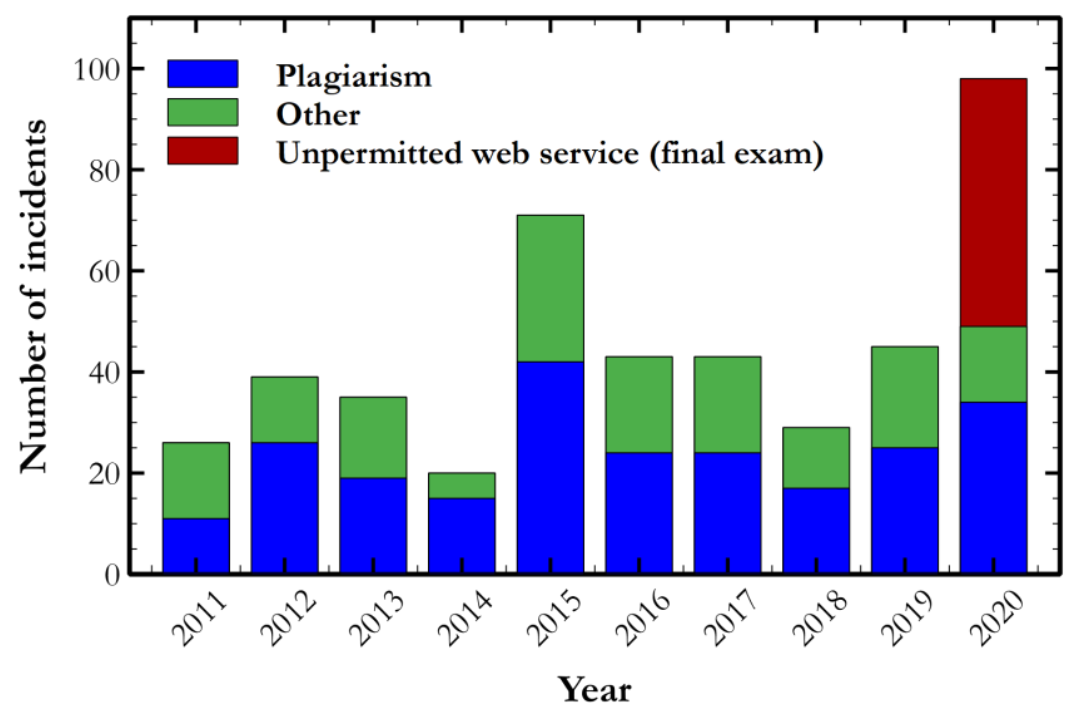

Figure 1. Incidents of academic misconduct by type at a large Canadian university for the past 10 years (e.g., 2020 indicates academic year ending on 30 June). The unique circumstances of the COVID-19 pandemic generated a new category of offence (red) as discussed in the text. (Data from University of Saskatchewan, 2020b)

\section{Student Engagement}

Students and instructors must be jointly invested in the course learning outcomes. This investment manifests as engagement with course material, including creating and accessing content in a timely manner and asking and answering questions. When engagement is lost, buy-in is lost, and students are less motivated to take the course seriously. A lack of student engagement may lead to increased instances of cheating (Kleinman, 2005; McCabe et al., 1999). We posit that the main conduit for maintenance of academic integrity lies in the free exchange of information between the instructor and the student. As soon as part of that flow is lost, students will replace it with communication with other students or third parties to ensure their grade is maintained or improved. The trust is lost - the students no longer trust the instructor to run the course in a predictable way, and the instructor no longer trusts the students to act in an honest scholarly manner.

If, for a temporary argument's sake, we view courses as products (a view the authors do not necessarily endorse), then the analogous prob- 
lem lies in marketing. An important goal of marketing is to engage with potential recipients and judiciously frame the product. Part of the marketing of a course should involve substantial engagement with students with expectations clearly laid out. A course is marketed through the calendar description, but also through the delivery of the content which, up until March 2020, had mostly been entirely in-person. Many courses included some form of interaction between students and instructors, through for example case study discussions or a flipped classroom design. The change to an online course therefore dramatically changed the product. Students may no longer have felt they were receiving what they had paid for, and might have responded by isolating themselves from the course and changing their attitude from one of "how can I do well in this class?" to "how can I pass this class and move on with my life?". Expectations were dramatically altered, and course engagement was put at serious risk.

To maintain engagement and manage student expectations with a view to promoting academic integrity, we advocate for a strategy that makes as little change as possible. When an instructor must move classes online fast, we recommend the following:

1. Keep the grading scheme the same, if possible. If you must implement a change, make it to the students' advantage by creating flexibility. For example, can the student choose to move a test's weight to an assignment?

2. Make weekly course announcements. Send them via email and post them on the course website. The announcement should have a one-sentence introduction to the week's material, bold any deliverables and explain how to submit, and include methods of contact should the students have questions. They may also include FAQ from the week before. A constant, predictable online presence may promote interaction between the students and the instructor, increasing feelings of accessibility.

3. Avoid expressions of uncertainty (e.g., "in these uncertain times...", "while we all learn to cope with this new normal...,", etc.). Students may view instructors as leaders, and in 
all times, a leader must show the path forward confidently.

While some instructors believe these expressions create an atmosphere of camaraderie and shared suffering, they can backfire very easily.

4. Keep the assessment submission system the same, if possible. If paper assignments had been handed in previously, ask students to send them via email. Students and instructors are already familiar with email, so the learning curve on how to submit assignments in this format is very flat. The digital divide between students who navigate well in online formats and those who do not may artificially negatively affect grades(Tien $\& \mathrm{Fu}, 2008)$. It is therefore best to have the capacity to maintain students' pre-remote learning and assessment strategies as faithfully as possible.

\section{Course Syllabi}

Setting aside the generalities of the course environment, engagement and expectations management may begin with the course syllabus. Students may be less likely to engage in activity that compromises academic integrity if this topic is explicitly addressed early on in their experience and revisited at subsequent intervals. Studies have explored this question and the general consensus appears to be that enhanced awareness of academic integrity as an issue, as well as the further step of socalled "honour pledges" reduce instances of violations (Mastin et al., 2009; McCabe et al., 1999).

A simple approach involves the creation of an academic integrity statement that students must sign before submitting coursework. An example is available online at the authors' institution (University of Saskatchewan, 2020a).

\section{Specific Assessments and their Setup}

Perhaps the most natural method of deterrence lies in the formulation of questions which are difficult to crowdsource. In quantitative courses, instructors frequently use calculation-based questions on assessments. Such questions, while useful for demonstrating understanding of a 
formula, are more problematic in an online setting (Trenholm, 2007a). It is more straightforward, for example, for a group of students to gather on social media and share answers to numerical questions. Questions that require calculation but then expand beyond simply providing a numerical result are less vulnerable to collusion. Instructor time commitment and likely student perceptions vary. In Table 1 we have provided an approximate time commitment and anticipated student response.

We consider multiple methods of assessment in an online format. Specifically, we examine how assignments, group work, tests and midterms, and final exams or course projects may be delivered remotely, while considering the potential for academic dishonesty and recommending methods of mitigation. We do not provide tips on detection of academic misconduct, as such a discussion is beyond the scope of this chapter.

\section{Assignments}

Before COVID-19, many instructors already provided assignment questions in a digital format. The change from in-person to online learning was therefore likely less dramatic from an assignment point of view. Students would already have known how to access the questions, and many would have already submitted their assignments online. The issues regarding academic integrity before the course went online are therefore the same as those afterward: are students working together, when they should be completing assessments individually? Are there any issues of plagiarism? In an online environment, instructors tend to believe students will collude more readily (Wiley, 2020), although this is a somewhat contentious topic (George \& Carlson, 1999; StuberMcEwen et al., 2009).

Fully online web-based assignments have other potential advantages for academic misconduct. By integrating feedback on student assignments with text mining to automatically alert students of the similarity of their work to others', plagiarism may be proactively reduced (Akçapinar, 2015). Of course, this would only apply to questions containing explanatory components. 
Table 1: Question types and impact on instructor time and potential student response

\begin{tabular}{|c|c|c|}
\hline Question & $\begin{array}{l}\text { Instructor time commit- } \\
\text { ment or concerns }\end{array}$ & $\begin{array}{l}\text { Anticipated stu- } \\
\text { dent response }\end{array}$ \\
\hline $\begin{array}{l}\text { Explaining a tech- } \\
\text { nical term in their } \\
\text { own words and } \\
\text { providing their own } \\
\text { example. }\end{array}$ & $\begin{array}{l}\text { Creating the question: minimal. } \\
\text { Marking the question: perhaps } \\
30 \text { seconds per student. } \\
\text { The technical term or terms } \\
\text { must be selected with care to } \\
\text { ensure multiple possible re- } \\
\text { sponses. }\end{array}$ & $\begin{array}{l}\text { If the concept has only } \\
\text { been explained one } \\
\text { way, then students may } \\
\text { rely on synonyms in- } \\
\text { stead of using their } \\
\text { own words. } \\
\text { Students for whom } \\
\text { English is an additional } \\
\text { language may find this } \\
\text { extremely difficult. }\end{array}$ \\
\hline $\begin{array}{l}\text { Forcing answers in } \\
\text { an online environ- } \\
\text { ment to be submit- } \\
\text { ted in a certain } \\
\text { period of time (e.g. } \\
5 \text { minutes per ques- } \\
\text { tion) }\end{array}$ & $\begin{array}{l}\text { Instructor must be comfortable } \\
\text { creating an online quiz, and the } \\
\text { quiz environment must be flexi- } \\
\text { ble enough to handle such a } \\
\text { restriction. If questions are also } \\
\text { randomized and/or drawn from } \\
\text { a question bank, then approxi- } \\
\text { mately } 2 \mathrm{x} \text { the number of ques- } \\
\text { tions on the quiz must be gener- } \\
\text { ated. This takes significant in- } \\
\text { structor time and effort, if the } \\
\text { instructor creates the questions. }\end{array}$ & $\begin{array}{l}\text { Students whose test } \\
\text { strategy involves tack- } \\
\text { ling "easy" problems } \\
\text { first will be pigeon- } \\
\text { holed into completing } \\
\text { each question individu- } \\
\text { ally. } \\
\text { Students who require } \\
\text { more than the average } \\
\text { amount of time per } \\
\text { question (for example, } \\
\text { due to accessibility } \\
\text { requirements) may be } \\
\text { at a disadvantage. }\end{array}$ \\
\hline $\begin{array}{l}\text { Creating a random- } \\
\text { ized set of numeri- } \\
\text { cal questions with } \\
\text { different numbers } \\
\text { for each student }\end{array}$ & $\begin{array}{l}\text { Instructor must be comfortable } \\
\text { creating an online quiz, and the } \\
\text { quiz environment must be flexi- } \\
\text { ble enough to handle such a } \\
\text { restriction. If questions are also } \\
\text { randomized and/or drawn from } \\
\text { a question bank, then approxi- } \\
\text { mately } 2 \mathrm{x} \text { the number of ques- } \\
\text { tions on the quiz must be gener- } \\
\text { ated. This takes significant in- } \\
\text { structor time and effort, if the } \\
\text { instructor creates the questions. }\end{array}$ & $\begin{array}{l}\text { Students tend to be } \\
\text { relatively familiar with } \\
\text { this style of test, and } \\
\text { are not likely to have } \\
\text { major concerns. }\end{array}$ \\
\hline
\end{tabular}




\begin{tabular}{|c|c|c|}
\hline Question & $\begin{array}{l}\text { Instructor time commit- } \\
\text { ment or concerns }\end{array}$ & $\begin{array}{l}\text { Anticipated stu- } \\
\text { dent response }\end{array}$ \\
\hline & $\begin{array}{l}\text { These questions are still relative- } \\
\text { ly easy to crowdsource. } \\
\text { Instructor must ensure students } \\
\text { are told how to round their } \\
\text { answer, if necessary. } \\
\text { Instructor must consider a pos- } \\
\text { sible tolerance for slight errors } \\
\text { in calculation - if the student } \\
\text { rounds intermediate calcula- } \\
\text { tions, for example, should they } \\
\text { still receive a mark for that } \\
\text { question? }\end{array}$ & \\
\hline $\begin{array}{l}\text { Create multiple } \\
\text { choice questions } \\
\text { with the same pre- } \\
\text { amble, but a differ- } \\
\text { ent question for } \\
\text { each student }\end{array}$ & $\begin{array}{l}\text { In large courses, a different } \\
\text { question for each student may } \\
\text { be infeasible; a question pool } \\
\text { with, perhaps, } 5 \text { - } 10 \text { questions } \\
\text { would suffice. } \\
\text { Time commitment: moderate in } \\
\text { terms of setup, minimal in } \\
\text { terms of marking assuming it is } \\
\text { marked automatically by a learn- } \\
\text { ing management system. }\end{array}$ & $\begin{array}{l}\text { Students may feel } \\
\text { 'tricked' if they attempt } \\
\text { to collude with others } \\
\text { when they see the same } \\
\text { preamble. This feeling } \\
\text { may translate to stu- } \\
\text { dents having negative } \\
\text { perceptions of the } \\
\text { instructor, and/or } \\
\text { possibly reducing their } \\
\text { engagement with the } \\
\text { course. }\end{array}$ \\
\hline
\end{tabular}

In general, a handwritten assignment (where work is expected to be shown in more detail) submitted digitally may be less likely to be vulnerable to plagiarism or collusion than an online assignment where a simple numerical answer is all that is required. Therefore, moving handwritten (or typed) assignments to a fully online environment is lower risk. Despite the additional marking time required, assignment questions which have an explanatory component both enhance assessment of student understanding and mitigate some potential for misconduct.

\section{Group Work}

There is a notable impact of group assessment formats on academic integrity. Academic integrity violations in a group setting may be less 
likely to take place than with individual assignments provided that at least one group member is diligent. On the other hand, there may also be a perception among students that "no one person is responsible" for any instances of plagiarism, which may reduce the sense of individual obligation to academic integrity. Online course environments should not hinder the use of this assessment format, especially given the ease with which students are able to engage with online collaboration tools (e.g., Google Documents). Indeed, adding intentionally collaborative assignments or other work may assist in mitigation of academic misconduct both from diligent students and by increasing overall engagement with the course community.

\section{Tests and Midterm Exams}

A large number of studies have focused on tests and exams with respect to issues of academic integrity in online courses (Allan, 2020; Bengtsson, 2019; Clark et al., 2020; D’Souza \& Siegfeldt, 2017; Feinman, 2018; Hart \& Morgan, 2009; Manoharan, 2019; van de Sande, 2018). Creating tests based on a test bank of instructor-generated questions is generally considered a robust starting point for quantitative courses (Clark et al., 2020). Using a textbook's provided online question bank can be problematic, as some students may have already accessed that resource and therefore would have an advantage over other students. Use of a provided test bank led to significant challenges in a nursing course at a Canadian institution, when that test bank's questions had been leaked online (CBC News, 2020). Students have already been primed to understand course concepts when they are explained by the instructor's unique writing style or speaking style. While creating a test bank takes significant time, it is better for the students and, ultimately, better from the point of view of academic integrity. Over time there is considerable time savings on the part of the instructor and the questions go through cycles of improvement with each use to weed out any errors.

Although proctoring is required in an in-person setting, in an online environment, it is much less useful. For example, in most proctoring software, it is impossible to tell whether a student has a separate device, out of the field of view, that may be used to contact another student. Additionally, a method of cheating advertised on social media has been to put a cheat sheet below the screen of one's laptop but above the keyboard, again out of the field of view. While some proctoring tools 
may offer 360-degree views of the student's environment, this introduces potential privacy concerns (Hylton et al., 2016). The videos resulting from the use of such software must be viewed by an appropriate proctor, and then properly stored and deleted after a certain period of time. Data storage in Europe, for example, has different implications from data storage in North America. Some Canadian institutions partner with American proctoring firms that result in student data being stored outside of Canada, which has other privacy concerns attached. Instead of expecting students to refrain from using course resources or cheat sheets during a test, it is undeniably more practicable to hold an open book test or exam. This is not an unpopular choice even for quantitative courses (Trenholm, 2007b).

However, without proctoring, it is natural to raise the question: how can I be sure the intended student is the one taking the test? This issue has been explored previously and there appears to be an alarming trend toward so-called "ghost students" for hire (Hollis, 2018). Impersonation during tests and exams is also a question during regular university operations for on-campus tests. For example, at the University of Waterloo, students are required to scan their student ID cards before beginning an exam (CTV Kitchener, 2014). One possible solution for an online format would be to require the student to take a picture of themselves next to their ID card, send it to the instructor or TA, and then at the beginning of the test, take a picture of themselves again to be submitted with the test. This is not a foolproof method and can easily be circumvented by students interested in contract cheating. However, it is also possible for contract cheating to go unnoticed in an in-person environment. In small online courses in which the instructor knows each student by name, and has interacted with each student visually, it may be possible for the photo approach to work because the student feels known by the instructor, which may deter unethical behaviour. In large courses, however, it is less likely that the instructor would know each individual. In an online environment, it is even less likely to be completely certain that the student is the person taking the test without use of proctoring software. Such software, however, is expensive and comes with complications as discussed above.

Finally, when is the best time to hold a test? Should there be dedicated class time during which the entire class must write, or should there be some flexibility? Although each instructor will feel differently, we recommend allowing a window of time during which students may write. 
In an online format, technological issues may arise that force a student to abandon a test prematurely. If the test must be completed during class time, then that student would inadvertently be given less time to write than others. Instead, offering the test during a large window of time (say, 12 hours), but limiting the amount of time during which the student may write (e.g., a limit of 1 hour for a test attempt), and offering multiple attempts, mitigates the technological issues that may arise. This method also allows flexibility in the time of writing for students to contend with, for example, work or familial obligations. In such a setup, it is best to have a test bank set up beforehand to allow each student to write a unique version of the test. It is also our recommendation not to have a time limit for each individual question on the test. For example, if the students are told in advance that they will have 5 minutes per question, some might be apprehensive because they know some calculations will take longer than others. Even if the allotted time is perceived by the course instructor to be more than enough, from a student perspective it is still an additional constraint that is perhaps unnecessary given the other restrictions that would already be in place. While a perquestion time limit may be the best option for preventing instances of academic integrity violations, the consequences are considerable.

\section{Final Exam or Course Project}

The final course assessment presents additional challenges as it is often the most heavily-weighted of the course. With a higher weight comes higher stress for students, and, naturally, a greater inclination toward cheating. Especially if the assessment is perceived as unfair (e.g., if it is perceived to include material that has never been directly covered in class, or material that was covered very briefly at the beginning of term, or material that was in supplementary files), or if the students have multiple final assessments on the same day (thus draining their intellectual capacity), there may be a tendency toward unethical behaviour. To mitigate this, some instructors might provide their exam days in advance without a time restriction and allow students to submit their work at any time up to the due date. This might be a less desirable course of action, as students would be able to post questions on subscription-based sites and wait for an answer to arrive (and indeed, as discussed earlier in this chapter, the risk of such cheating is substantial). Nearly half of the authors' institution's 49 formal academic dishonesty cases involving a particular subscription-based digital resource were from two courses which employed this exam strategy. Posting an exam 
with a window of days to complete, while a generous option, does not serve the cause of academic integrity. Instead, if an exam must be conducted, we recommend timed randomized online examinations in quantitative courses.

Another common form of final assessment is a course project. In such a setting, students may be given a case, or set of general problems and asked to solve them using course concepts. While it is possible to individualize course projects, for introductory-level quantitative courses it is not always feasible as the students do not have sufficient domain knowledge to handle the various types of analysis required. Instead, students are often all given the same set of questions to work on, or a selection among a fixed set of questions. If this is intended to be a group project, then such a set of questions is appropriate. However, if the assessment is to be completed individually, this setup may unintentionally allow academic misconduct. When all students have the same questions, they will likely work together to find the answers, treating the assessment more as a group assignment than a summative evaluation. To avoid this, working the student's ID number into each question is one possible course of action. However, for the course of pandemic remote learning, we recommend timed exams in lieu of course projects, as they are more secure from an academic integrity standpoint.

\section{Conclusions and Summary of Recommendations}

In the pandemic context, when an instructor must move a course online quickly, it is best to keep as much as possible the same. Students have already developed learning and assessment strategies for the inperson setting. In an atmosphere in which everything else is uncertain, the constancy of a familiar course with clear expectations can be a lifeline. Specifically, we recommend keeping the assessment weights and methods of submission as similar as possible to their in-person counterparts, avoiding expressions of uncertainty, and maintaining a predictable online presence in the course. By keeping students informed each week of their obligations, they may be less likely to fall behind and therefore less likely to resort to covert methods to pass the course.

Regardless of whether an online course is developed intentionally, it is crucial to have a clear communication and assessment plan. We recommend that, in an online format, timed midterm tests and the final 
exam be constructed using randomized questions from an instructorcreated question bank. We also encourage a wide time interval of test availability with multiple time-constrained attempts, with the highestscoring attempt counting as the grade on the test. This strategy promotes student buy-in by allowing student choice - they can take the test again if they do not like their grade. The wide time interval allows students to review their notes between attempts, which has anecdotally been observed to be a popular strategy. We recommend limiting the number of attempts to two or perhaps three, to avoid an unnecessary time commitment from both the students (writing three tests in one day is intellectually draining) and the instructor (creating three separate randomized tests takes substantial time and energy). We believe that assignments need not change dramatically, but the introduction of a component of group work may promote healthy conversations among students on course content. In summary, we have five key recommendations:

1) Keeping assessment weights and assignment submission mechanisms as similar as possible when moving a course online (to maintain student expectations);

2) Creating and maintaining a consistent online presence (to promote student engagement);

3) Avoiding expressions of uncertainty, and leading with intention (to create an atmosphere of trust);

4) Including a discussion on academic dishonesty in the syllabus and using an academic integrity statement with each assessment submission;

5) Constructing randomized timed tests and exams based on instructorcreated questions, with a wide time interval of availability and two or three attempts.

While the COVID-19 situation is still unfolding at the time of writing, we believe these recommendations may be studied in real course environments in the manner of Clark et al., 2020 and Asgari et al., 2020. We hope that after sufficient study, these strategies will be widely adopted by instructors of quantitative courses both in business settings and in the general academic community. 


\section{References}

Akçapinar, G. (2015). How automated feedback through text mining changes plagiaristic behavior in online assignments. Computers and Education, 87, 123-130. https://doi.org/10.1016/j.compedu.2015.04.007

Allan, S. (2020). Migration and transformation: A sociomaterial analysis of practitioners' experiences with online exams. Research in Learning Technology, 28, 2020. https://doi.org/10.25304/rlt.v28.2279

Asgari, S., Trajkovic, J., Rahmani, M., ... W. Z. preprint arXiv, \& 2020, U. (2020). An Observational Study of Engineering Online Education During the COVID-19 Pandemic. Arxiv.Org. https://doi.org/10.1109/ACCESS.2020

Baron, J., \& Crooks, S. M. (2005). Academic integrity in web based distance education. TechTrends, 49(2), 40-45. https://doi.org/10.1007/bf02773970

Beckman, T., Lam, H., \& Khare, A. (2016). Learning assessment must change in a world of digital "cheats." In Phantom Ex Machina: Digital Disruption's Role in Business Model Transformation (pp. 211222). Springer International Publishing. https://doi.org/10.1007/978-3-319-44468-0_14

Bengtsson, L. (2019). Take-home exams in higher education: A systematic review. In Education Sciences (Vol. 9, Issue 4). https://doi.org/10.3390/educsci9040267

Bullingham, L., \& Vasconcelos, A. C. (2013). “The presentation of self in the online world": Goffman and the study of online identities. Journal of Information Science, 39(1), 101-112. https://doi.org/10.1177/0165551512470051

CBC News. (2020, February 1). Pirated test bank answers circulated among students compromised nursing exam, Brandon University says. https://www.cbc.ca/news/canada/manitoba/brandon-universitynursing-exam-compromised-update-1.5448882

Clark, T. M., Callam, C. S., Paul, N. M., Stoltzfus, M. W., \& Turner, D. (2020). Testing in the Time of COVID-19: A Sudden Transition to Unproctored Online Exams. Journal of Chemical Education. https://doi.org/10.1021/acs.jchemed.0c00546 
CTV Kitchener. (2014, December 18). University staff were tipped off about fake student IDs being used in math exam.

https://kitchener.ctvnews.ca/university-staff-were-tipped-offabout-fake-student-ids-being-used-in-math-exam-1.2154642

D'Souza, K. A., \& Siegfeldt, D. V. (2017). A Conceptual Framework for Detecting Cheating in Online and Take-Home Exams. Decision Sciences Journal of Innovative Education, 15(4), 370-391. https://doi.org/10.1111/dsji.12140

Feinman, Y. (2018). Alternative to proctoring in introductory statistics community college courses [Walden University]. https://scholarworks.waldenu.edu/dissertations

George, J. F., \& Carlson, J. R. (1999). Group support systems and deceptive communication. Proceedings of the Hawaii International Conference on System Sciences, 25. https://doi.org/10.1109/hicss.1999.772722

Greaser, J., Black, E. W., \& Dawson, K. (2008). Academic dishonesty in traditional and online classrooms: does the "media equation" hold true? Online Learning, 12(3). https:// doi.org/10.24059/olj.v12i3.13

Hallett, D. H. (2000). Teaching quantitative methods to students of public affairs: Present and future. Journal of Policy Analysis and Management, 19(2), 335-341. https://doi.org/10.1002/(sici)15206688(200021)19:2<335::aid-pam10>3.3.co;2-1

Hart, L., \& Morgan, L. (2009). Strategies for online test security. Nurse Educator, 34(6), 249-253. https://doi.org/10.1097/NNE.0b013e3181bc743b

Hollis, L. P. (2018). Ghost-Students and the New Wave of Online Cheating for Community College Students. New Directions for Community Colleges, 2018(183), 25-34. https://doi.org/10.1002/cc.20314

Holzweiss, P. C., Joyner, S. A., Fuller, M. B., Henderson, S., \& Young, R. (2014). Online graduate students' perceptions of best learning experiences. Distance Education, 35(3), 311-323. https:// doi.org/10.1080/01587919.2015.955262

Hylton, K., Levy, Y., \& Dringus, L. P. (2016). Utilizing webcam-based proctoring to deter misconduct in online exams. Computers and Education, 92-93, 53-63. 
https://doi.org/10.1016/j.compedu.2015.10.002

Jaggars, S. S. (2013). Choosing Between Online and Face-to-Face Courses: Community College Student Voices | Shanna Smith Jaggars. CCRC Working Paper No. 58, 10027(58), 1-28. https://www.tandfonline.com/doi/abs/10.1080/08923647.2014. 867697

Keramidas, C. G., Ludlow, B. L., Collins, B. C., \& Baird, C. M. (2007). Saving Your Sanity When Teaching in an Online Environment: Lessons Learned. Rural Special Education Quarterly, 26(1), 28-39. https://doi.org/10.1177/875687050702600105

Kleinman, S. (2005). Strategies for Encouraging Active Learning, Interaction, and Academic Integrity in Online Courses. Communication Teacher, 19(1), 13-18. https://doi.org/10.1080/1740462042000339212

Kocdar, S., Karadeniz, A., Peytcheva-Forsyth, R., \& Stoeva, V. (2018). Cheating and Plagiarism in E-Assessment: Students' Perspectives. Open Praxis, 10(3), 221. https://doi.org/10.5944/openpraxis.10.3.873

Lau, L. K., Caracciolo, B., \& Scroggins, A. (2012). College students' perception of ethics. Journal of Academic and Business Ethics, 5, 113.

Lee-Post, A., \& Hapke, H. (2017). Online learning integrity approaches: Current practices and future solutions. Online Learning Journal, 21(1), 135-145. https://doi.org/10.24059/olj.v21i1.843

Manoharan, S. (2019). Cheat-resistant multiple-choice examinations using personalization. Computers and Education, 130, 139-151. https://doi.org/10.1016/j.compedu.2018.11.007

Marques, T., Reis, N., \& Gomes, J. (2019). A Bibliometric Study on Academic Dishonesty Research. Journal of Academic Ethics, 17(2), 169-191. https://doi.org/10.1007/s10805-019-09328-2

Mastin, D. F., Peszka, J., \& Lilly, D. R. (2009). Online Academic Integrity. Teaching of Psychology, 36(3), 174-178. https://doi.org/10.1080/00986280902739768

McCabe, D. L., Trevino, L. K., \& Butterfield, K. D. (1999). Academic integrity in honor code and non-honor code environments: A 
qualitative investigation. Journal of Higher Education, 70(2), 211234. https://doi.org/10.1080/00221546.1999.11780762

Patnaude, K. A. (2008). Faculty perceptions regarding the extent to which the online course environment affects academic bonesty (Issue August) [University of Houston]. https://queens.ezp1.qub.ac.uk/login?url=https://search.proquest .com/docview/304602304?accountid=13374\%0Ahttp:/ / resolver. ebscohost.com/openurl?ctx_ver=Z39.882004\&ctx_enc $=$ info:ofi/enc:UTF8\&rfr_id=info:sid/Education + Database\&rft_val_fmt $=$ info:ofi $/ \mathrm{f}$ mt:kev:mt

Peterson, J. (2019). An Analysis of Academic Dishonesty in Online Classes. In Mid-Western Educational Researcher (Vol. 31). https://www.mwera.org/MWER/volumes/v31/issue1/V31n1Peterson-FEATURE-ARTICLE.pdf

Reynders, G., \& Ruder, S. M. (2020). Moving a Large-Lecture Organic POGIL Classroom to an Online Setting. Journal of Chemical Education. https://doi.org/10.1021/acs.jchemed.0c00615

Streseman, M., \& Millican, J. (2020). The Ethics of Chegg. The Journal of the TTU Ethics Center, 4(2).

https://journals.tdl.org/ttuec/index.php/ttuec/article/view/54

Stuber-McEwen, D., Wiseley, P., \& Hoggatt, S. (2009). Point, Click, and Cheat: Frequency and Type of Academic Dishonesty in the Virtual Classroom. Online Journal of Distance Learning Administration, 12(3 Fall), 1-9. https://www2.westga.edu/ distance/ojdla/fall123/stuber123.ht $\mathrm{ml}$

Tien, F. F., \& Fu, T. T. (2008). The correlates of the digital divide and their impact on college student learning. Computers and Education, 50(1), 421-436. https://doi.org/10.1016/j.compedu.2006.07.005

Trenholm, S. (2007a). A Review of Cheating in Fully Asynchronous Online Courses: A Math or Fact-Based Course Perspective. Journal of Educational Technology Systems, 35(3), 281-300. https://doi.org/10.2190/y781-h21x-241n-7q02

Trenholm, S. (2007b). An investigation of assessment in fully asynchronous online math courses. In (C) International Journal for 
Educational Integrity (Vol. 3, Issue 2).

http://www.ojs.unisa.edu.au/journals/index.php/IJEI/

University of Saskatchewan. (2020a). Academic Integrity and Remote

Teaching. Gwenna Moss Centre for Teaching and Learning - The

Official Blog of the GMCTL.

https://words.usask.ca/gmcte/2020/03/18/academic-integrityand-remote-teaching/

University of Saskatchewan. (2020b). Student Conduct and Appeals

Statistics. https:// secretariat.usask.ca/student-conductappeals/index.php

van de Sande, C. (2018). Perceptions of Cheating on Online versus

Face-to-Face Mathematics Exams. In EdMedia+ Innovate Learning (pp. 2132-2137). Association for the Advancement of Computing in Education (AACE). https://www.learntechlib.org/p/184529/

Wiley. (2020). Academic Integrity In the Age ofOnline Learning.

https://teachingcommons.lakeheadu.ca/sites/default/files/inlinefiles/academic-integrity-in-the-age-of-online-learning.pdf 

Cheong, C., Coldwell-Nielson, J., MacCallum, K., Luo, T., \& Scime, A. (Eds.). (2021). COVID-19 and Education: Learning and Teaching in a Pandemic-Constrained Environment.

Santa Rosa, California: Informing Science Press. (pp. xx-xx). 